\title{
A Brief History of Serious Games
}

\author{
Phil Wilkinson \\ The Centre for Excellence in Media Practice, Bournemouth University, Bournemouth, UK \\ pwilkinsonebournemouth.ac.uk
}

\begin{abstract}
Serious Games are now an established field of study. In this field most would attribute the rise of Serious Games to Clark C Abt's creation of the term in 1970, or indeed Ben Sawyer's popularization of it in 2002. However, considering the rich history of purposing non-digital games, itself preceded by discussions of purposing play that are traceable to the work of Plato, it can be said that Serious Games is a contemporary manifestation of centuries old theories and practices. In this chapter, we explore the pre-history of Serious Games, beginning with the suggested purpose, and purposing of play. Throughout this historical review we identify key in research and practice that are apparent in the contemporary Serious Games field.
\end{abstract}

Keywords: serious games · play $\cdot$ simulation-based learning $\cdot$ game-based learning $\cdot$ games for social change $\cdot$ games for health $\cdot$ playful learning

\section{Introduction}

"As important new research begins in such matters as the cognitive implications of play, the sociology of sport, simulations in education, and interaction behavior, it is vital that researchers and students have easy access to some of the major historical and current information on the study of games, and of play. "[1]

Serious Games as a field of study did spring into existence. There is a rich, interdisciplinary history that has converged into the current Serious Games ecosystem. Tracing back this convergence reveals historical trends emerging from fundamental discussions exploring the very notion of play itself. Furthermore, concepts prevalent in contemporary Serious Games discussion are often concepts from historical fields that have been reapplied. Therefore, to take the study of serious game seriously it is necessary to consider these historical origins. These trends and concepts are apparent when exploring the application of games, their conceptualisation, and their evaluation.

For instance, exploring the application of games for purposes other than entertainment has a historical precedence in the application of play - especially in educational contexts. Plato, for example, philosophised that reinforcing certain behaviours exhibited in play would reinforce those behaviours as an adult. Indeed, it can be argued that from the 19th century onwards it has been assumed that children's play and games are a developmental imperative. Seminal development psychologist Jean Piaget even goes 
so far as to suggest "play is the work of children" [2] - a philosophy apparent in contemporary Serious Games development. Other contexts that have become key adopters and developers of Serious Games have a similar history.

Chaturgana - argued by historians to be the precursor to chess - developed in $7^{\text {th }}$ Century India, was the first game, on record, to explicitly apply a militaristic metaphor to a board game [3]. Taking this as a starting point, we can then trace this militaristic application of games to more recognisable digital Serious Games such as America's Army. Paralleling this historical application of games in educational and military contexts, there are examples of pre-digital games designed to enact social change and the governmental application of games for serious purposes. For instance, the Landlord's Game, created in 1902 and precursor to Monopoly, was designed to illustrate the dangers of capitalist approaches to land taxes and property renting [3].

Interweaving this historical contextual adoption of Serious Games, both analogue and digital, is the development of conceptualisations relating to their application. For instance, the often repeated notion of the 'magic circle' developed by play theorist Johan Huizinga was conceived to describe imaginary play spaces [4]. Additional key terms such as engagement, interaction, or flow emerged from the fields of education, computer scie nce, and positive psychology. These cross-over terms applied in Serious Games can be viewed as the attempted ludic framing of theories, models, and frameworks from other fields.

This development and dismissal of theories and approaches can be applied to Serious Games development and evaluation. The field of Serious Games sometimes suffers for its interdisciplinarity due to inconsistent definitions, evaluation methods, and multiple conceptualisations. However, there is potential for Serious Games research to benefit from the historical precedents set out by its converging disciplines. As a recent metaanalysis suggests [5], the majority of educational Serious Games do not explicitly adopt a key learning theory. Additionally, the same methodological problems of ecological invalidity and prescriptive, lab-based play evaluations in the 1970s [2] are apparent in some contemporary Serious Games evaluative studies [6, 7].

\section{Chapter Overview}

"Yet individuals can once again become involved, and thought and action can again be integrated, in games created to simulate these social processes. The zest for life felt at those exhilarating moments of history when men participated in effecting great changes on the models of great ideas can be recaptured by simulations of roles in the form of Serious Games" [8]

Given the intercontextuality and interdisciplinarity of Serious Games, it would be impossible for any researcher to be familiar with the rich, dynamic history of every informing discipline. The goal of this chapter is to retroactively apply contemporary discussions, approaches, and applications of Serious Games onto historical precedents. In this we will map a developmental trajectory for Serious Games research, beginning with early philosophical discussions. 
Plato's early discussions regarding the purpose of play - and to an extent, the purposing of play - mark a starting point in a millennia old debate. This debate surrounding play's purpose has direct implications for the study of Serious Games, especially in relation to educational applications. Of course part of this play-debate is the conceptual difficulty in defining play resonated with contemporary difficulties in defining Serious Games. In addition, lessons can be taken forward from attempts to research and measure play during the height of the behaviourist psychological paradigm.

Paralleling and interweaving with this debate are, of course, discussions about the applications of games. The distinction between play and games is as contentious as their singular definitions. Application of games - specifically for serious purposes throughout history will be highlighted. From this we will see a pattern of purposing and contextual adoption that emerges. Moreover, when we cast current, generally accepted definitions of a serious game back, we can reveal a rich history of purposing games that reflect current, formalised approaches.

The term Serious Games can be traced to the seminal work of Clark Abt [8]. Through this work, coupled with the rising popularity of video games in popular culture, contemporary uses of the term Serious Games imply a digital form. As will be demonstrated there historically, multiple non-digital examples. For the sake of posterity this chapter will view the Serious Games development trajectory in relation to the development of digital Serious games - that is, pre- and post-digital. Pre-digital will include the aforementioned debates surrounding play, key examples, and related fields of simulation-based learning. Post-digital will highlight the continuation of historical trends as they converge on contemporary research into Serious Games.

In addition, the development of Serious Games will be discussed in relation to the increased legitimization of entertainment games. As media theorist Henry Jenkins suggests:

"Games represent a new lively art, one as appropriate for the digital age as those earlier media were for the machine age. They open up new aesthetic experiences and transform the computer screen into a realm of experimentation and innovation that is broadly accessible" [9]

Henry Jenkin's framing of the development of the digital games field as creating increased capacity for experimentation and innovation directly speaks to contemporary understandings of Serious Games. It illustrates the link between the development of entertainment game technologies and their application in Serious Games.

Finally, writing on the emerging field of pre-digital games-based learning, particularly in reference to his own city administration game Metropolis Richard Duke suggested that "gaming is a future's language, a new form of communication emerging suddenly and with great impact across many lands and in many problem situations." [10] Converging this with Jenkin's assertion that games are "the thing that pushes forward innovation and experimentation." [9], we are well positioned to take the developmental trajectories discussed in this chapter and make reasonable speculations about future trends. 


\section{Purpose of Play}

"II] a boy is to be a good farmer or a good builder, he should play at building toy houses or at farming and be provided by his tutor with miniature tools modelled on real ones. ... One should see games as a means of directing children's tastes and inclinations to the role they will fulfil as adults." - [11]

Plato's proposal that play can be used to guide a child's development and, by extension, suggests that play can be educationally purposed [11]. However, despite this proposal of purposing, up until the end of the $18^{\text {th }}$ century play was viewed as something to be curtailed in children. It was only with the works of Enlightenment philosophers Friedrich Schiller and Jean-Jacques Rousseau that we began to consider play a right of childhood [2]. Through their work we began to recognise a contemporary framing of play as an intrinsically purposeful activity.

In play theorist David Cohen's extensive review of play he suggests that the early $19^{\text {th }}$ century saw the development of "enlightened laws [giving] children a kind of freedom which they had never had before. If they used some of that freedom to play, then play had to have some purpose." [2] He argues that there is an implicit assumption not often examined - that play must serve some purpose, even after removing the suggested guided structuring of play put forward by early play-based educationalist Frobels and Montessori.

Through this ongoing discussion regarding the purposing of play, it appears there is an increase in perceived complexity regarding play. Moving from play is a necessity for expelling excess energy, towards an evolutionary perspective of play as the development of skills needed for survival or the cathartic practice of primitive behaviours $[2,12]$. As playful behaviour is exhibited across the animal kingdom - with greater frequency in youth - Groos' evolutionary theory is still present even in neuroscientific enquiries into play [13].

Taking an, admittedly, much broader and encompassing understanding of the purpose of play, Johan Huzinga argued that play itself is a foundational necessity of cultural development. In his seminal work Homo Ludens - or playing man - he begins from a similar starting point to Hall and Groos, that is, examining what meaning we can take from existence of play in the animal kingdom. For Huzinga this demonstrated that play predates cultured society and play itself is culturally generative, that is "culture arises in the form of play, that it is played from the very beginning" [4]

In addition to Huzinga's exploration of the play element of culture - that is how culture itself exhibits playful qualities - he is perhaps best known for his conception of the magic circle. This conception was an attempt to capture the physical or metaphysical boundaries of play spaces - "All play moves and has its being within a play-ground marked off beforehand either materially or ideally, deliberately or as a matter of course" [4]. In contemporary digital game studies, this notion of a distinct space in which play happens is readily applied to the virtual spaces of digital games [14-16]

Although the magic circle has become a key concept in game studies - popularised by game studies researchers Katie Salen and Eric Zimmerman [14] it has seen limited 
application to Serious Games [17]. One example creates a salient discussion of the necessity of understanding the magic circle, or how this play space can be broken, in games-based learning [18]. Although the magic-circle can be blurry, increasingly so with the rise of pervasive games [19], it has interesting implications for Serious Games. For instance, the notion that boundaries between playing and not playing are "fuzzy and permable" [14] directly speaks to the inherent tension of balancing fun and purpose in Serious Games design [20].

While the magic circle is especially relevant today, current discourse has also been informed by other early theories of play - especially those that discuss play's purpose. Social learning theorist Lev Vyogtosky conceptualised play as wish fulfilment in which children use their imaginations to free themselves from immediate situational constraints [21]In addition, Vygotsky believed that "[i]n play a child always behaves beyond his average age, above his daily behavior; in play it is as though he were a head taller than himself"' [21].

Vygotsky's contemporary, Jean Piaget, argued that play affords the consolidation of existing skills through repetition - as well as developing a sense of mastery. Counter to the other theorists mentioned here, Piaget paid little direct attention to the role of play. However, his focus on cognitive stages of development informs the work of psychologists who seek to categorise play stages [2]. As such children's play - or capacity for specific types of play - is used as a means of assessing their developmental stage (Broadhead, 2006). Following the work of early educational-play theorists is a pervasive notion of play's role in children's cognitive, emotional, and social developmental (Bergen, 2002; Pellegrini, 2009).

Furthermore, pretend play in which a child roleplay societal characters - a doctor or fireman for example - can be seen as the child exploring cultural norms [2, 22, 23]. This underlying assumption of play's purpose is apparent in modern digital play activities - as evidenced by contemporary discussions exploring the role of digital games in expressing and reinforcing socio-civic norms [24, 25]. As play has been repeatedly framed as having an intrinsic developmental purpose, this same notion of purpose has been applied to modern digital video games [26-28].

Given the pervasiveness of this assumed purpose of play, it is perhaps inevitable the same assumption has extended to digital games. As seminal sociologist Erving Goffman suggests - "[t]he function of play has been commented on for many centuries, to little avail" [29].Reflecting this functionalist approach to understanding play - assuming that it must serve some purpose - is the functionalised approach. Following the logic that play must indeed be a purposeful activity, and therefore serves a purpose, it can be assumed that play can indeed be purposed. Here we have an emergence of the key tension of between play, fun, and entertainment and the underlying purposes of Serious Games.

Reflecting the inherent tension of balancing fun and purpose in Serious Games is the work of French Sociologist Roger Caillois. In Man, Play and Games [30] Caillois comprehensively develops the work of Johan Huzinga through categorizing play. For Calliois, play existed on a spectrum from ludus (etymological origin for the term ludology, frequently applied to the field games studies) or game to padia or free play. He also argued here there is a human tendency to move from paida to ludus play. This has 
interesting implications for the Serious Games field, perhaps an extreme example of moving from free-play to purposeful rule-based games. In addition, it also speaks to the historical approach of functionalising play.

\section{$4 \quad$ Purposing Play for Learning}

"The playing adult steps sideward into another reality; the playing child advances into new stages of mastery. I propose the theory that the child's play is the infantile form of the human ability to deal with experience by creating model situations and to master reality by experiment and planning. " [31]

Given Plato's assertion that the play of the child shapes their development into adulthood, in conjunction with humanistic psychologist Erik Erikson suggestion of the developmental potential of play, it is understandable that play has so frequently been purposed for learning. As previously touched upon, this notion of purposing play has existed alongside the idea that play has an intrinsic - if ineffable - purpose. Revisiting Rousseau we see that his advocacy for the rights of citizens, and for the right for children to "eat, run, and play as much as they please" [2] touches upon a blurred notion of children's play as work. This notion of the child's right to play is now legally mandated in under the United Nations Convention on the Rights of the Child [32].

For Rousseau "to a child of 10 or 12, work or play are all one" [2]. The influence of Rousseau's work is apparent in the playful approach to early years' education pioneered by Frobel and Montessori. It is worth noting however, that both educationalists believed in the need for purposing, or controlling, play. Frobel's kindergartens predominantly used teacher-directed imaginative play. For Montessori, her often misinterpreted quote "play was the work of the child" [2] referred to her encouraged practice of object-based real-world interaction, not to free, unguided play.

This notion of harnessing the captivating nature of play and by extension the stratification of different types of play in terms of their development value has persisted. For instance, Montessori's focus on object-based real-world play stood in opposition to the teacher-guided imagination-based play of Frobel [2]In the western cultures this attitude pervades as an expectation of parents to play with their children, an expectation that frequently places the developmental nourishment of real-world play in opposition to digital-play.

Indeed, digital technology is often framed as destroying childhood [33, 34]. Of course, this has direct implications for the perception of digital games as developmentally important in play $[27,35,28]$. When discussing the role of digital Serious Games in children's education it is worth considering this cultural context. It should, however, be noted that this attitude is not universal. As described by Gaskins, Haight, and Lancy [36], we can categorise cultural expectations of play's developmental significance into three areas.

Western society broadly fits into a cultural category of cultivating play, in that play is actively encouraged in children. This is in opposition to 'culturally curtailed play', where children are dissuaded from play; and 'culturally accepted play', in which play 
is expected but not encouraged. Viewing the Western development of play expectations then, it is perhaps little surprise that the expectations placed on parents to encourage play with their children are mirrored in parents' expectation of schools. A 2009 report funded by the UK Government Department for education found out of 952 parents surveyed "over $90 \%$ [were in] agreement that young children should have fun and learn through play at primary school" [37]. Moreover, it is worth considering that advances in Serious Games have typically emerged from this western cultural context, particularly the US $[8,38]$.

Given this expectation of younger children to learn through play perhaps explains the prevalence of Serious Games - particularly learning games - for younger learners [39]. Of course this expectation of play-based learning has created a tension in marrying curricular expectations and playful pedagogies [40]. It is worth recognising that just as the popularity of purposing play for learning reflects the popularity of educational Serious Games, there are other historical purposes of play that are reflected in contemporary Serious Games. Education therefore is not the only purposing of play that directly speaks to current applications of Serious Games.

\section{$5 \quad$ Purposing Play for Therapy}

"Play is the highest development in childhood, for it alone is the free expression of what is in the child's soul. ... Children's play is not mere sport. It is full of meaning and import". [41]

This position of play, interpreted by early educational-play theorist Frobel, is the core of the historical development of play as therapy. For Froebel, play can be seen as an expression of internal experiences - especially through symbolic or imaginative play [2]. However, the notion of play's internal reflectivity can be traced, again, back to the $18^{\text {th }}$ century work of Jean-Jacques Rousseau. In his seminal text Emile, or On Education, Rosseau highlights the importance of understanding children through observing them in play $[2,42]$.

Tracing the historical development of play as a therapeutic medium we reveal two justifications for play's application here. First, as Rosseau and Froebel suggested, play can be viewed as a window into the child's inner experiences - a justification that is used for current therapeutic Serious Games [43]. Secondly, it is also suggested play is the natural behaviour of the child, so engaging in therapeutic activity through play allows for a naturalistic approach that puts the child at ease [42]. It is interesting that this second justification has familiar echoes in the justification for the use of games in therapeutic settings, and indeed education [44] due to children's familiarity and comfort with the medium.

Given the assumption that play provides a window into the internal representations of the child, it is of little surprise that this approach was adopted in early psychoanalytical approaches. In fact, the first case of applying play in a therapeutic setting can be traced to Sigmund Freud. In his treatment of a young boy suffering from a phobia he suggestion to the parent to observe the boy's play at home to provide insight into his 
mental state [2, 42]. As well as this play-analysis approach developed by Freud - and further expanded by Madeleine Klein - was Anna Freud's use of play as a means of developing child-therapist relationships [2, 42, 45].

It is perhaps the work of humanist psychologist Carl Rogers in play therapy that has the greatest significance for play therapy today - and by extension the therapeutic use of Serious Games. Rogers pioneered the client-centred approach to therapy, highlighting notions of self-determination and an internal desire for self-actualisation on the part of the client [46]. This was developed by the work of Viginia Axline who in effect - operationalised the humanist paradigm set-forth by Rogers in the form of child-centred play therapy [47].

For Axline "A play experience is therapeutic because it provides a secure relationship between the child and the adult, so that the child has the freedom and room to state himself in his own terms." [47]. Currently, this child-centred play therapy is the most popular approach, with the largest body of research, in therapeutic practice [42, 48]. Taking this historical perspective of play therapy into account, in addition to an awareness of current practices, we can see multiple implications for the application of Serious Games for therapeutic purposes.

The assumption of children's natural desire to be playful in the current context of digital games' prevalence is often used a justification which is frequently made explicit $[43,49]$. Similiarly, the justification of play-based therapies as allowing for the child to freely express themselves resonates with current discourse arguing that Serious Games application affords degrees of freedom not otherwise available. Furthermore, it has direct implications for therapeutic Serious Games developers as they consider player agency [50], or the creation of virtual safe-spaces [51].

Blurring the line between the - admittedly already blurry - boundary of Serious Games and serious application of entertainment games, we can see the application of play based therapies in other therapeutic contexts such as cognitive behavioural therapies $[49,52]$. There is indeed increasing interest in the use of entertainment game as a means of building rapport, or fostering therapist-child relationships [49, 53]. However, counter to historical applications of play as a means of developing positive researcherclient relationships, it has been suggested that current uses of digital-play based interventions may undermine this relationship [54].

We must acknowledge that, like playful learning and the broader Serious Games eco-system, we have predominantly focussed on the child. However, in the current social construction of childhood as an opportunity for play - even if it is directed - it is perhaps now little surprise that the number of Serious Games reflect this. Returning to our original quotation of Plato - "one should see games as a means of directing children's tastes and inclinations to the role they will fulfil as adults." [11] - we see traces of our final historical play-precedent for Serious Games. 


\section{$6 \quad$ Purposing Play for Social Control}

"No society has ever really noticed how important play is for social stability. My proposal is that one should regulate children's play. Let them always play the same games, with the same rules and under the same conditions, and have fun playing with the same toys. That way you'll find that adult behavior and society itself will be stable." [11]

Although this is third time we return to Plato, it is because his self-proclaimed ground-breaking work has such implications for the purposing of play. In this instance though, we refer to his specific suggestion of the need to, or the potential of, regulating play. Play theorist David Cohen's review of play is, at times, critical of the attitudes informing early play conceptions [2] He argued that the work of Froebel and Montessori were largely informed by puritan attitudes of the time, in that it was expected that leisure time was to be spent bettering oneself. This notion frames the motivation playbased learning less as less rooted in pedagogic rationale, and more in reflecting the societal expectations of the time.

Prescribing playful activities, as Plato directly suggests and Cohen implies in the approach of early play theorists, can be viewed as a means of directing and controlling children's behaviour such that you control their developmental trajectory. This readily reflected in the discourse surrounding cognitive, physical, and socio-emotional development of children through play-based learning. It can also be argued that through prescriptive play you are able to control the development of their socio-cultural attitudes.

For play theorist David Cohen, the early work of play educationalists and practitioners was an attempt at control - a perspective reflected in Brian Sutton-Smith's extensive historical and rhetorical unpacking of play [55]. Between 1890 and 1920, the American government spent $\$ 100$ million creating playgrounds across America. Sutton-smith argues that this investment was predominantly a means of implicitly training youngsters to become integrated into, and productive members of, society.

This notion of play-spaces as a means of cultivating desired cultural and societal values can be traced to the work of Henry Curtis. In Curtis' Education Through Play, we see the purpose of play for social cultivation emerge - Curtis suggests that "the idleness of the street... is morally dangerous" [2]. Developing Sutton-Smith's argument, Cohen surmises that "Western societies have used play to make children conform" [2]. Following this, there is indeed a rise in the use of Serious Games for changing or cultivating social attitudes $[27,56,57]$.

In addition, when applying this notion of control to Serious Games more broadly, we can begin to unpack implicit societal messages. For instance, the frequently referenced America's Army - a training and recruitment game - we can see a societal message promoting militarism [58]. The notion of using play to encourage children to conform can be seen as echoing, on a societal level, the application of play in mediating learning or therapy. It can be argued that this same philosophy of purposing play as a means of cultivating desired behaviours can be applied to Serious Games. Frequent justifications for the use of Serious Games are their perceived 'holding power' [59], and ability to engage and motivate players $[60,61]$ 
From this we can see how this historical approach to purposing play has direct implications for the application areas of Serious Games. Play is well established, from the perspective of academic inquiry and socio-cultural expectations, as a means of engaging children in educational, developmental, and therapeutic activities. Perhaps most significant, however, is the broader approach of purposing play and games. Therefore, the rich history of inquiry and discussion surrounding the purpose and purposing of play directly resonates with contemporary applications of Serious Games.

Having established that there is indeed antecedence in historical research - and broader socio-cultural expectations of play - that informs current approaches to Serious Games, it is necessary to narrow our focus to games specifically. The following sections will outline approaches to purposing non-digital games, before moving on to the purposing of digital games - or what we would recognise as Serious Games research. First however, it is worth considering historical research into games more broadly as there are parallels to be drawn with the contemporary legitimization of Serious Games research.

\section{$7 \quad$ Emerging Study of Games}

"The comparative study of games is one that deserves a high place among our inquiries into the history and development of culture. Their origin belongs to the time preceding that of written records; and many games were not only the product of primitive conditions, but represent the means by which man endeavored to bring himself into communion with and to penetrate the secrets of the natural powers that surrounded him." [62]

The historical study of non-digital games has seen an oscillation of regard. Stewart Culin's seminal work in the late $19^{\text {th }}$ and early $20^{\text {th }}$ elevates games as something worthy of study. Despite the historical antecedents and contemporary elevation of the significance of play at the time of Culin's work, games were still seen as having limited significance for research. This is remarked upon by W. H. Holmes, the Director of the Bureau of American Ethnography, when reporting on Culin's exploration of the Games of North American Indians in 1903:

"The popular notion that games ... are trivial in nature and of no particular significance as a subject of research soon gave way, under the well-conducted studies of $\mathrm{Mr}$ Culin, to an adequate appreciation of their importance as an integral part of human culture" [63]

Culin's work preceded Johan Huizgina's book Homo Ludens [4], Roger Caillois work Man, Play and Games [30], and seminal games studies such as The Kissing Games of Adolescents in Ohio [64]or Children's Games in the Street and Playground [65]. With regards to Huizinga and Caillois especially, their work directly builds upon Culin's position that games are significant for cultural inquiry as their origin "preced[es] that of written records" [62]. For Huizinga and Caillois play and games both formed and are informed by culture, as evidenced by their existence prior to human civilization. 
In theory then, it could be said that Culin's work provide a turning point in promoting serious academic inquiry into games. However, as discussed in the preceding section, there is still non-trivial philosophical discussion of games. Even if this philosophical inquiry doesn't hold the same rigour as the ethnographic study of Culin's and those that followed, it still demonstrates that games were seen as worth 'serious' consideration.

It can be argued that Culin's pioneering studies of games - counter to notions of games triviality at the time - are reflected in the contemporary pioneering of Serious Games and advocates of their legitimacy [66, 67]. Additionally, this movement towards taking games - and Serious Games - 'seriously' is not a linear process but one of ebbs and flows. As suggested by Jasper Juul [68], supported by the work of Elliot Avedon and Brian Sutton Smith [1], there is a historical oscillation of regard for the significance of games. When mapping this historical antecedent onto contemporary work in Serious Games it is perhaps not surprising then that Clark Abt's foundational work [8] was comparatively ignored until the beginning of the $21^{\text {st }}$ century. ${ }^{1}$

Within this broader academic shifting of priorities is a field specific changing of priorities in what is considered 'serious' inquiry. Current academic focuses on Serious Games can be considered interdisciplinary but there are dominant disciplines within this eco-system. What is evident when exploring historical academic consideration of non-digital games is there is dominance of anthropological and ethnographic approaches [1]. This stands in contrast to the current study of Serious Games research dominated by social sciences, psychology, and, naturally, fields from computing.

What does this mean for the study of Serious Games? Firstly, like historical studies of games, Serious Games has not followed a consistent linear path of legitimisation, but instead moves in stops and starts. For instance, the Clark Abt introduced the term 'Serious Games' in 1970, however, according to Tarja Susi [69] and Damien Djaouti [38] it wasn't until 2002 that 'Serious Games' came into wide usage. This dynamism is reflected in the shifting consensus on what constitutes 'serious' Serious Games research - that is, which research should be prioritised in the field. Additionally, there is again historical precedent for the purposing of games - which will be explored here - amongst the broader shifting academic landscape.

\section{Origins of the Purpose and Purposing of Games}

"[Here] the general position taken is that a game performs something of a bridge function in development. It allows for the expression of given impulses but at the same time safeguards the players by putting limits on the way in which those impulses can be expressed." [64]

The above quote is taken from The Kissing Games of Adolescents in Ohio by Brian Sutton-Smith [64], in this he concludes that games do indeed serve a role in chil-

${ }^{1}$ Based on number of Citations from 1970 to 1990 compared with 1991 to 2016 
dren's development. For Sutton-Smith, games offer an opportunity for children to express themselves in a safe-space that provides rule-based boundaries to help shape their expressions. This notion of games as providing a space for children's safe exploration of necessary skills or social practices builds directly on notions of play's purpose in their development. There is however, a distinction to be made here that follows Roger Caillois's conception of a ludus - paida spectrum [30].

The distinction between play and games can be centred on the introduction of rules - systematic boundaries, taking different forms, that shape playful activities. It is in this distinction that we move away from the perceived intrinsic purpose of free-play, and the intentional purposing of games through the intentional construction of gamerules. This purposeful construction of games as rule-based systems formed a key starting position in the rise of 'simulation gaming' throughout the mid- $20^{\text {th }}$ century.

According to Wolf and Crookall, "the modern era of simulation/gaming began in the late 1950s" [70]. They argue that it emerged through a combination of "wargaming' practices, and new educational theories that prioritised active participation such as experiential learning [71]. Indeed, these same theories of experiential learning are apparent in contemporary Serious Games approaches [60, 69, 72]. Wolf and Crookall also acknowledge a historical precedence in this as they suggest war-games were formerly introduced in the $17^{\text {th }}$ and $18^{\text {th }}$ century - discounting war-themed "parlour games" chess and Chaturanga [70].

Given this historical integration of game-based training in military contexts across multiple centuries, it is perhaps unsurprising that this would have a role in the development of simulation-gaming. Even less surprising then is its consideration as the forefront of modern Serious Games practices, as exemplified by leading Serious Game America's Army. The rise of simulation-based learning - and the rise of Serious Games - perhaps owes much to historical military training practices. From the 1950s onwards commercial organisations began to adopt simulation-based learning practices.

Simulation-based learning, with its military origins and supported by the emergence of participatory theories of learning, was seen as a necessity given the rising complexity of real-world practices. However, simulation-game rules could be constructed to accurately reflect complex social, economic, and political systems. Writing on the subject, simulation-based learning pioneer Richard Duke suggests that:

"Gaming / Simulation is one device that is useful for presenting a dynamic model which is an abstraction of complex reality .... Games can be viewed as abstract symbolic maps of various multidimensional phenomena." [10]

In Duke's writing we can again see a justification for the use of non-digital games-based learning practices, which also hold true for modern Serious Games practices. However, it can be suggested that Serious Games extends and builds upon this justification, as digital technologies offer greater representational affordances.

As touched upon earlier in this chapter, Duke became an advocate for simulationbased learning practices, as evidenced by his seminal book Gaming: The Future Language. Here again we can draw parallels with the same - at times - evangelical rhetoric surrounding the 'power' of Serious Games, and an anticipatory excitement for their potential across multiple domains [6, 57, 69, 73-76]. Writing on the subject of Simulation gaming in 1995, taking a historical perspective of the preceding 35 years, Wolfe 
and Crookall identified several impediments to the field - directly related to this sense of interdisciplinary excitement:

"The field [Simulation-Based Learning] often celebrates its interdisciplinary nature and recognizes it's diverse origins. This very nature, however, encourages a lack of independent structure, a lack of recognition by the established disciplines and sciences, and a free-form orientation that often attracts the temporary interest of dilettantes who soon move onto other fancies without leaving much of an important. " [70]

Interestingly, this passage can be readily applied to the current Serious Games ecosystem. An excitement across multiple disciplines has created a fractured field of study [72]. Moreover, this fractured excitement has a role in creating somewhat superficial or as Wolf and Crook describe, 'dilettante' - research and developmental practices. This is evidenced by limited empirical Serious Games evaluations [60, 77] and a lack of integration of theories of learning into educational Serious Games [5].

A justification for the purposing of simulation based learning, alongside following theories of experiential learning, is the affordance of holistic representation. Learners participating in a simulation of policy and resource management with Richard Duke's Metropolis [10]for example, would be presented with a representation of all of the processes inherent in this. Therefore, this would lead to a gestalt understanding of the overall system. Again, this follows comparable justifications for Serious Games especially those that attempt to develop appreciation for social systems, or an empathy for the social issues that arise in these systems [57, 73].

With analogous simulation-based learning then, there are parallels to be drawn with contemporary Serious Games. There is a comparable diversity of application domains and interest across academic disciplines - in itself leading to tensions as the field develops. Moreover, contemporary Serious Games follow similar justifications of experiential, problem-based, and situated learning theories. Serious Games indeed follows the same trajectory of simulation-based learning. Moreover, the frequency with which the two fields are discussed together, or conflated, speaks to an intertwined ongoing development [72].

Serious Games as understood today, however, is built on the rise of digital technologies. With this rise of digital learning practices, Serious Games' focus extends beyond representation of social systems and includes individualistic approaches to knowledge acquisition and skills development, following behaviourist and cognitivist theories of learning. At this point we can follow the trends identified in the foundational - yet analogous - pre-history of Serious Games towards their digital manifestation. Before doing so however, it is necessary to consider the seminal work of Clark C Abt.

In his book Serious Games Clark Abt [8]identifies justifications, contextual applications, and conceptual definitions of contemporary Serious Games that are predictive, if not directly foundational. Moreover, this work provides an historically situated anchor point that illustrates both the movement from simulation-based learning to games-based learning as separate practices and the seemingly natural transition from analogous to digital Serious Games. 


\section{$9 \quad$ Emergence of Serious Games as a Field}

"Games may be played seriously or casually. We are concerned with 'Serious Games' in the sense that these games have an explicit and carefully thought-out educational purpose and are not intended to be played primarily for amusement. This does not mean that serious game are not, or should not be, entertaining. ” [8]

Abt is often credited with coining the term 'Serious Games' [38, 69]. From the above quote we can see that he provided the foundation for modern definitions of Serious Games that frame them as games designed for a purpose beyond entertaining - though these games are indeed still entertaining. What is striking however, when reading Abt's seminal work Serious Games, is his identification of the key justifications for using contemporary Serious Games.

For Abt, Serious Games provide an opportunity to address the "motivational inadequacies" of the American educational system. They also provide representational affordances, and therefore different opportunities for engagement, of complex organizational or socio-political systems. Finally, bridging the historical purposing of play as 'safe exploration' and modern justifications of Serious Games, he suggests that "Simulations or games offer an inexpensive and relatively unthreatening means of experimentation" [8]

Moving on from the specific form of Serious Games, Abt also discussed their contextual adoption. For instance, with educational Serious Games, Abt discusses the teacher's practices of their adoption arguing that: "the timing of a classroom game should be made to maximize the game's dramatic impact on the students" and the importance of debriefing or "postgame analysis" [8]Moreover, he paints the use of these educational Serious Games as decidedly social affairs with learners collaborating or competing within the game. The contextual consideration and social approach of the Serious Games Abt describes stands in near-contrast to contemporary practices, which prioritise personalised and individualistic Serious Games design.

More broadly, Abt also identifies that one of the key considerations for Serious Games adoption is not just their effectiveness, but their cost-effectiveness.

"[A] ssessing the value of games and whether they are, in fact, 'worth the trouble' means that we must assess their cost-effectiveness, their efficiency in comparison to other instructional and research methods. "[8]

Indeed, Abt's broader considerations of an emerging Serious Game eco-system also extend to the necessity of answering "skeptics" [8] - a process of legitimization that is still apparent in contemporary work [66, 67]. Furthermore, in Abt's initial unpacking of the notion Serious, he refers to the games themselves, but also the pursuit of Serious Games research. This, of course, has implications for the broader field of Serious Games studies:

"The term 'serious' is also used in the sense of study, relating to matters of great interest and importance." [8]

It is worth noting that although Abt has a clear history in the field, his seminal work which has become foundational in contemporary Serious Games pursuits is written 
largely anecdotally. Moreover, his work still predominantly focussed on analogous simulation games, speaking to his experience and the broader popularity of the approach [78]. However, he does include digital Serious Games in his discussion and does so rather straightforwardly. He states that "It is possible, of course, to make a computer simulation of a game" [8]. Throughout his book Serious Games references to computer based simulations as a logical, and expected extension of pre-existing simulation-based learning practices.

America's military had been experimenting with computer simulation-based learning since the end of World War 2. In 1948, AIR DEFENSE SIMULATION was completed and actively used for military training [79]. Of course this was a rather rudimentary visual representation, overlapping sophisticated mathematical models, of enemy aircraft and anti-air weapons. This was followed by the development of CARMONETTE (Combined Arms Computer Model) in 1953 and deployed in 1956 which expanded upon AIR DEFENSE SIMULATION to include a richer virtual representation, including infantry, radio-communications, and tanks [79].

Considering the historical military application of simulation gaming and early military experiments with computer-modelling, it is not surprising that they began developing what we may consider Proto-Serious Games as early as 1948. Moreover, at the time of Abt's writing updated Serious Games in 1985, it is less surprising that there were "400 major computer war games" [8] already developed. For Abt then, digital Serious Games were merely an extension of the previous simulation-based learning approach.

Writing in 1985 he was, however, disappointed when reflecting upon the previous 15 years of computer simulation-based learning development. In updating Serious Games, Abt reflected on the 15 years since his original publication and lamented a lack of progress in the "analytical, educational, evaluative and predictive quality" [8] of computer simulation games. Furthermore, although he acknowledged that digital Serious Games were indeed being used in the classroom, they were overshadowed by the development of computer games primarily for entertainment.

At this point in the chapter, with Abt's Serious Games as our historical nexus, we will move from discussing the non-digital incarnation of Serious Games and narrow our focus onto the contemporary field. From the 1970s onwards, the development of Serious Games became an increasingly reified field, distinct from both analogous play or game-based practices; and other computer based instructional methods. During this time there was the rise of the video game industry and human-computer interaction fields of study occurring in parallel with the rise of the contemporary Serious Games research field.

\section{From Analogue to Digital Serious Games:}

"[C]omputer games have become a larger mix of entertainment rather than instruction, and the market for entertainment games with minimal instructional content has completely outdistanced the market for instructional games, however entertainingly computerized". [8] 
At the time of writing Serious Games there was a tentative adoption of educational Serious Games in the classroom. Lemonade Stand, a text based business simulation game, was developed and used in the classroom in 1973; followed by, the now famous, Oregan's Trail in 1974 [38]. It is interesting that Abt expresses a disappointment in the rise of games that prioritise entertainment, seemingly at the cost of instructional content. This creates an interesting point of departure for the work of Abt for two reasons.

First, Abt was perhaps unable to predict the use of commercially available entertainment games in an educational context [80]. Secondly, most importantly, there is a lack of consideration here for the potential of the rising entertainment games industry in driving forward the Serious Games eco-system. There was indeed a rise of arcade games and personal home consoles towards the latter end of the $20^{\text {th }}$ century [81]. For some this presented an opportunity for developing Serious Games that build upon preexiting games and can be more widely disseminated through at-home consoles.

Following the trend of military experimentation, The Bradley Trainer was a game developed in cooperation with the US Military and Atari. In 1980 Atari had just published their arcade cabinet game Battlezone, in which players would use a periscope attachment to target and shoot enemy vehicles. For the US Army's The Bradley Trainer, this same game mechanic was seen as a training simulator for, then new, Infantry Fighting Vehicles (IFV). However, custom assets were added to the game including replacing the fantasy shells of Battlezone, with ammunition types carried by actual IFVs and enemy tank models were changed to reflect the silhouettes of realworld tank types [82].

During this same time period, commercial organisations also began to repurpose exiting game technologies for advertising. For instance, Pepsi Invaders was developed in 1983 for sales employees of Coca-Cola as a means of fostering company moral in relation to their Coca-Cola's rival. As the title suggests, Pepsi Invaders was a near identical copy of the classic video game Space Invaders - with alien spaceships replaced with the letters P-E-P-S-I [38]. However, Pepsi Invaders was intended for internal usage whereas its contemporaries Kool-Aid Man, or Chex Quest were designed specifically for brand promotion through home video game consoles [38].

With the examples of Kool-Aid Man and Chex Quest we see the emergence of Serious Games designed for advertising commercial products specifically to children - a trend that is apparent in modern advergaming research [83]. With these games, The Bradley Trainer included, we can see the burgeoning influence of the commercial video games market on Serious Games. In these cases, we can again see the historical trend of using the engagement or motivational potential of games.

In the healthcare context, the early examples of using video games for rehabilitative practices were framed around their engagement potential [84, 85]. For rehabilitation, video games were seen as a way of overcoming initial resistance to therapy, distracting the patients focus away from pain, and avoiding repetitive or boring rehabilitative exercises [84, 85]. Furthermore, video game usage in psychotherapeutic settings were initially justified following the same logic of using play-based therapy. That is, video games were seen as a means of building rapport, managing behaviour, or observing children's internalised thought processes through their game-play behaviour $[53,86]$. 
Given the rising popularity of video games and the perceived engagement of the player, there was an outcry discussing their potential addictive nature [87, 88]. As media theorist, and socio-technological commentator Sherry Turkle describes it:

"There has been controversy about video games from the days of Space Invaders and Asteroids, from the time that the games' holding power provoked people who saw it as a sign of addiction to become alarmed. The controversy intensified as it became clear that more than a "games craze" was involved. This was not the Hula-Hoop of the 1980s" [88]

It is this notion of the video games "holding power" as described by Turkle that has particular relevance here. For all of the discussion of video games engagement potential, this was indicative of early scholarly works specifically discussing this engagement potential. Indeed, Turkle's work The Second Self is perhaps the first instance in which Mihaly Csikszentmihalyi's theory of 'flow', now ubiquitous in Serious Games research $[89,90]$, was specifically applied to video games.

Preceding Turkle, Thomas W. Malone in 1980 had already begun researching the underlying intrinsic motivational potential of video-games form a cognitive psychologist perspective [91]. With this work Malone created a taxonomy of motivational principles from games that could be used to inform instructional design. This psychological perspective of motivation was paralleled in Minds at Play, a book written by Geoffrey and Elizabeth Loftus. In this they argue that part of the 'holding power' of video games is due to their 'partial reinforcement' [87] of play behavior.

Loftus and Loftus argue that the rewarding but unpredictable nature of video games feedback leads to a continued desire from the player. Interestingly, this is reflected in modern neuroscience studies tracking the release of dopamine - understood as the 'desire' chemical - during game play [92]. Furthermore, this approach of random reward intervals has been adopted by Serious Games to promote engagement [93, 94]. Therefore, as exemplified in Malone's discussion of applications of instructional video games, there was a rise of Serious Games that adopted this 'games-as-motivation' approach.

As identified by the work of Damien Djaouti and others, there was a rise in the number of Serious Games for education from 1980 to 2002 [38]. However, there was an expression of dissatisfaction by some educational technology theorists, and researchers, at the rather simplistic form of these games. For Seymour Papert - founder of constructionism and pioneer of games design as a pedagogic approach - educational Serious Games of the time were Shavian reversals [95]. That is, they adopted the worst practices of their parent disciplines thus forming games that were primarily drill and practice quizzes in which the player is motivated through behaviourist notions of reinforcement [96].

It is worth noting that this, unfortunate, trend towards ludic incentivised quizzes or rote skills practices - is apparent today [75]. Indeed, the popular framing of Serious Games as 'chocolate-covered brocoli', initially conceived by Amy Bruckman and presented at the 1999 Games Developers Conference [97], is readily apparent in contemporary Serious Games discourse [98]. Indeed, this approach is now often, derisively, 
referred to as edutainment - the field of designing typically traditional media for educational purposes. However, during this time period there were other independently constructivist notions of educational Serious Games.

Seriously Considering Play [99], the seminal work of Lloyd Rieber was published in 1996. In this work Rieber maps the constructivist notion of a microworld - a selfcontained, complete, and internal representation of a domain of interest - with the fantastical representations of games. Rieber, and others [100] argued that his fantasy element leads to engagement with the learning content. Here then, in the work of Rieber we have a logical extension of the approach of Malone - that is the segmenting of 'games' into a set of heuristics that can be used to form Serious Games design.

This work to unpack, stratify demarcate, or otherwise categorize games into a set of heuristics or design principles to be applied to educational games was a significant focus for researchers at the time [101]. Moreover, when reviewing the modern trends in Serious Games research, it is apparent that this trend has continued - though the models are now more formalised [38, 102-104]. From the mid-1980s to late 1990s the continued research into stratifying game elements to be purposed for their learning was paralleled with a marked decline in the number of studies looking at non-digital educational Serious Games [96] - emphasizing a shift towards the digital.

In 2001 Espen Aarseth published the article Computer Game Studies, Year One in the first "first academic, peer-reviewed journal dedicated to computer game studies" [105]. In this, as the title suggests, he positions 2001 as Year 1 of computer games studies. That is, computer games had become a credible, international, academic field as evidenced by the founding of the first peer-reviewed journal and international scholarly conference dedicated to the field [105].This illustrates a step in academia to legitimize the field of Game Studies - with obvious implications for the field of Serious Games. Following the work of Aarseth, and borrowing his moniker, the following year can be framed as Year One of Serious Games.

\section{Serious Games Studies, Year One}

In 2002, Rosemary Garris, Robert Ahlers, and James Driskell produced a comprehensive review of pre-existing research into educational Serious Games [101]. This review is illustrative for three reasons. Firstly, Garris and Ahlers published the work whilst working for the US Naval Air Warfare Center for Training Systems Division demonstrating the military's continued role in driving forward Serious Games research. Secondly, they review the work of existing researchers with a view to develop a model for educational Serious Games, in itself illustrative, but also it represents a shift towards more formalised models. Finally, in the article though they describe their work as developing instructional games they highlight the oxymoronic tensions of their terminology:

"Huizinga argued that the "fun element" underlies the intensity, absorption, and power of games and that play is the direct opposite of seriousness. As we adapt games for serious purposes, we must be aware of this tension between the world of play and 
the world of work. Thus, in one sense, the term instructional game is an oxymoron." [101]

In the article though they refer to their field as instructional games, their repeated reference to the notion of 'serious' is very timely. In the same year Ben Sawyer would release the foundational white paper Serious Games: Improving Public Policy through Game-based Learning and Simulation [38, 69]. This paper and the soon to follow launch of the Serious Games Initiative would cement the term Serious Games in popular academic discourse when discussing the purposing of games. Here then, we enter what is framed by most as the contemporary era of Serious Games [38, 69].

In 2002 the commercial video game market had grown significantly [106]. Therefore, in Ben Sawyers discussion of the potential of Serious Games, he identified a need to link the commercial video game industry with contextual applications [38, 69]. This approach of comparing the approaches of the video game industry with educational practitioners, highlighting how the former can inform the latter, became a key pillar at the foundation of Serious Games.

Mark Prensky popularised this comparative discourse in his first book Digital GameBased Learning [44]. In this he explicitly compares the entertainment game and educational trainer industries - highlighting the energy and excitement on display at the Electronic Entertainment Expo (E3):

"Today's trainers and trainees are from totally separate worlds. The biggest underlying dynamic in training and learning today is the rapid and unexpected confrontation of a corps of trainers and teachers raised in a pre-digital generation and educated in the styles of the past, with a body of learners raised in the digital world of Sesame Street, MTV, fast movies and "twitch speed" videogames." [44]

For Prensky then it was not so much an opportunity for educational practitioners to borrow from the games design principles and practices of the commercial video games industry, it was a necessity. Of course, Prensky is now well-known in educational Serious Games circles for furthering this rhetoric. Though perhaps slightly dogmatic, in 2001 he captured a desire - that had been growing since the work of Malone and Turkle in the early 1980 s - to apply commercial digital game design in educational contexts. Currently, this same inter-contextual sharing of practices is readily apparent and formalised through the establishment of academia, industry, and application domain networks.

At this point in this chapter it is necessary to acknowledge that since starting the discussing of the Serious Games history, post invention of the computer, we have focused primarily on educational Serious Games. As is now apparent however, this is fitting with the historical development of purposeful analogous or digital games and simulations. That is, the historical analogous games, and indeed the computer-based proto-Serious Games were primarily designed for learning.

In Damien Djaouti and others [38] historical review of Serious Games, starting with early computer games, from 1980 to 2002 they identified 953 Serious Games. Moreover, of these 953 Serious Games 'ancestors' $65.8 \%$ could be categorised as educational [38]. From Serious Games' Year One, 2002, through to 2010 there was a marked increase in the total number of Serious Games however, the proportion of educational games dropped to $25.7 \%$. This reduction of the proportion of educational Serious 
Games was of course the result of an increased diversity of purpose in the emergent field of Serious Games.

Here then, we have a dramatic shift in the field of Serious Games as the diversity of their application grew. For instance, as identified in their work Djaouti [38] identifies that between 2002 and 2010, 30.7\% of the Serious Games developed were designed for advertising. Indeed, following 2002 the newly founded Serious Games Initiative had a role in developing the application of Serious Games in social activism, and healthcare. In 2004 the first Games for Change conference was held and thus a formalised network of non-profits and experts emerged to explore the potential of Serious Games for tackling social issues [57]. In this same year the Games for Health conference was also first held to explore the potential of Serious Games in healthcare [107].

Given the increasing application of Serious Games across multiple contexts scholars in the emerging field began to wrestle with Serious Games definition. Currently, the issue of defining Serious Games is still prevalent. However, definitions that are presented are frequently a derivative or slight re-interpretation of 'games that have a purpose beyond entertainment' $[38,69]$. Indeed, these definitions are often traced to works of David Michael and Sande Chen [108] or Michael Zyda [109]:

"Games that do not have entertainment, enjoyment, or fun as their primary purpose." [108]

"Serious game: a mental contest, played with a computer in accordance with specific rules, that uses entertainment to further government or corporate training, education, health, public policy, and strategic communication objectives. ” [109]

As with the other critical periods of history identified here, this wrestling over defining the term Serious Game is a trend with historical origin that continues to this day. The difficulty of defining 'play' or 'games' - or even the impossibility of the task [110] - only adds to the difficulty of defining both 'serious' and 'games' in conjunction. As Crookall suggests however, despite this difficulty in definition the field as a whole will continued to move forward:

"I am sure that some dust will continue to fly for the next few years, maybe decades, and that researchers and developers will continue to do their thing, despite the arguments one way or the other with regard to the term 'serious'." [72]

\section{Conclusion}

"Serious gaming seems to have captured the imagination of, and drawn strong support from, many well beyond the actual gaming world. Even governments are providing support for serious games, with recent examples including a major thrust by the French Government, funding by the U.S. Institutes for Health and a European Union grant for the GaLA network. Surely that is a good thing. "[72]

In Crookall's review of the current state of Simulations and Gaming at the $40^{\text {th }}$ Anniversary Symposium of $S \& G$, he directly acknowledges the rise of Serious Games. In his article, as illustrated in his quote here, he optimistically addresses the popularity of 
Serious Games and their inter-contextual appreciation. At the time of Crookall's writing this review, Serious Games had already become an established academic field of study evidenced by the founding of The Serious Games Institute at Coventry Univesity in 2007.

Currently, as signposted by Crookall, Serious Games are an increasingly interwoven practice across multiple domains. Indeed, Serious Games had transitions from exploratory, or fringe, experiments, to an increasingly legitimized medium for education, healthcare, and social change. In the coming together of these domains, the field of study has become increasingly interdisciplinary. Starting with rather simple origins in the convergence of computational modelling and non-digital game-based learning, now the field of Serious Games is a nexus for multiple other disciplines - as evidenced by the breadth of topics covered in this book.

If we were to revisit the slightly romanticised rhetoric of Richard Duke and Henry Jenkin's ,their positioning of games as a 'language of the future' [10] and 'the new lively art' [9] has become manifest in the contemporary field of Serious Games. Serious Games research and practices are beginning to shape the practices of the contexts they are used in. However, as we have identified in this chapter, like Duke and Jenkins, perhaps we could have seen this coming. There are historical antecedents to Serious Games in the form of purposing of play and games. Additionally, beginning with these antecedents, we can see trends emerge, and the same challenges facing previous researchers are still apparent.

There is still a pre-eminence of educational applications for Serious Games and the research field itself is still driven forward by external partnerships - particularly the military. Moreover, the difficult of pin-pointing the first Serious Game as we understand it today, speaks to current debates in their definition. Again, a debate that has existed since the researchers began to study 'play'. Another key characteristic that is apparent through the history and pre-history of Serious Games is an optimistic sense of expectancy of the potential of games. This sense of expectancy was perhaps best captured by the work of Duke and Jenkins - written 33 years apart. So it can be said then that games and by extension Serious Games are a language and a medium of the future but with a rich and storied past.

\section{References}

1. Avedon, M.E., Sutton-Smith, B.: The Study of Games. Ishi Press International, California (2015).

2. Cohen, D.: The Development of Play Third Edition. Routledge, London (2007).

3. Parlett, D.S.: Oxford History of Board Games. Oxford University Press, Oxford (1999).

4. Huizinga, J.: Homo Ludens: A Study of the Play-Element in Culture. Beacon Press, Boston (1971).

5. Wu, W.H., Hsiao, H.C., Wu, P.L., Lin, C.H., Huang, S.H.: Investigating the learning-theory foundations of game-based learning: A meta-analysis. J. Comput. Assist. Learn. 28, 265279 (2012). 
6. DeSmet, A., Van Ryckeghem, D., Compernolle, S., Baranowski, T., Thompson, D., Crombez, G., Poels, K., Van Lippevelde, W., Bastiaensens, S., Van Cleemput, K., Vandebosch, H., De Bourdeaudhuij, I., Hospital, G., Street, T., Gard, T., Hoge, E.A., Kerr, C.: A Meta-Analysis of Serious Digital Games for Healthy Lifestyle Promotion. Prev. Med. (Baltim). 69, 95-107 (2014).

7. Mayer, I., Bekebrede, G., Harteveld, C., Warmelink, H., Zhou, Q., Van Ruijven, T., Lo, J., Kortmann, R., Wenzler, I.: The research and evaluation of serious games: Toward a comprehensive methodology. Br. J. Educ. Technol. 45, 502-527 (2014).

8. Abt, C.C.: Serious Games. University Press of America (1987).

9. Jenkins, H.: The Wow Climax: Tracing the Emotional Impact of Popular Culture. New York University Press, New York (2007).

10. Duke, R.D.: Gaming, the future's language. John Wiley \& Sons, New York (1974).

11. D'Angour, A.: Plato and Play: Taking Education Seriously in Ancient Greece. Am. J. Play. 5, 293-307 (2013).

12. Wood, W.: CHILDREN' S PLAY And Its Place in Education. Routledge, New York (2012).

13. Wang, S., Aamodt, S.: Play, stress, and the learning brain. Cerebrum. 2012, 12 (2012).

14. Salen, K., Zimmerman, E.: Rules of Play: Game Design Fundamentals. The MIT Press (2003).

15. Juul, J.: The Magic Circle and the Puzzle Piece. Conf. Proc. Philos. Comput. Games 2008. 56-67 (2008).

16. Rodriguez, H.: The playful and the serious: An approximation to Huizinga's Homo Ludens. Game Studies. 6, (2006).

17. Klopfer, E., Osterweil, S., Salen, K.: Moving Learning Games Forward. Flora. 3, 58 (2009).

18. Remmele, B., Whitton, N.: Disrupting the Magic Circle: The Impact of Negative Social Gaming Behaviours. In: Psychology, Pedagogy, and Assessment in Serious Games. pp. 111126. IGI Global (2014).

19. Montola, M.: Exploring the edge of the magic circle: Defining pervasive games. In: Proceedings of DAC. p. 103 (2005).

20. Franzwa, C., Tang, Y., Johnson, A.: Serious game design: Motivating students through a balance of fun and learning. In: Games and Virtual Worlds for Serious Applications (VSGAMES), 2013 5th International Conference on. pp. 1-7. IEEE (2013).

21. Vygotsky, L.: Interaction between learning and development. Readings Dev. Child. 23, 3441 (1978).

22. Schwartzman, H.: Transformations: The anthropology of children's play. Springer Science \& Business Media (2012).

23. Lillard, A.S., Lerner, M.D., Hopkins, E.J., Dore, R.A., Smith, E.D., Palmquist, C.M.: The impact of pretend play on children's development: A review of the evidence. Psychol. Bull. 139, 1 (2013).

24. Flanagan, M., Nissenbaum, H.: Values at Play in Digital Games. MIT Press, Cambridge, Massachusetts (2014).

25. Saomya, S.: Kurt Squire on Civic Engagement Through Digital Games, https://edtechreview.in/e-learning/558-civic-engagement-through-digital-games.

26. Verenikina, I., Harris, P., Lysaght, P.: Child's Play: Computer Games, Theories of Play and Children's Development. Proc. Int. Fed. Inf. Process. Work. Gr. 3.5 open Conf. Young Child. Learn. Technol. - Vol. 34. 99 - 106 (2003).

27. Prensky, M.: "Don't bother me Mom, I'm learning!": how computer and video games are preparing your kids for twenty-first century success and how you can help! Paragon House (2006).

28. Gee, J.P.: What video games have to teach us about learning and literacy. (2003). 
29. Goffman, E.: Replies and responses. Lang. Soc. 5, 257-313 (1976).

30. Caillois, R., Barash, M.: Man, play, and games. University of Illinois Press (1961).

31. Erikson, E.H.: Childhood and society, 2nd. New York WW. (1963).

32. Detrick, S.: A Commentary on the United Nations Convention on the Rights of the Child. Martinus Nijhoff Publishers (1999).

33. Buckingham, D.: After the Death of Childhood. Blackwell (2008).

34. Buckingham, D., Chronaki, D.: Saving the Children? Presented at the (2014).

35. Gee, J.P.: Learning and games. Ecol. Games Connect. Youth, Games, Learn. 21-40 (2008).

36. Gaskins, S., Haight, W., Lancy, D.F.: The cultural construction of play. Play Dev. Evol. Sociocult. Funct. Perspect. 179-202 (2007).

37. Education, D. for: Working Together, Achieving More. , London (2009).

38. Djaouti, D., Alvarez, J., Jessel, J., Rampnoux, O.: Origins of Serious Games. Serious Games Edutainment Appl. 25-43 (2011).

39. Ritterfeld, U., Cody, M., Vorderer, P.: Serious games: Mechanisms and effects. Routledge (2009).

40. Fisher, K.R., Hirsh-Pasek, K., Golinkoff, R.M., Gryfe, S.G.: Conceptual split? Parents' and experts' perceptions of play in the 21st century. J. Appl. Dev. Psychol. 29, 305-316 (2008).

41. Froebel, F.: The education of man. A. Lovell \& Company (1885).

42. Landreth, G.L.: Play therapy: The art of the relationship. Routledge (2012).

43. Martins, T., Carvalho, V., Soares, F., Moreira, M.F.: Serious game as a tool to intellectual disabilities therapy: Total challenge. In: Serious Games and Applications for Health (SeGAH), 2011 IEEE 1st International Conference on. pp. 1-7. IEEE (2011).

44. Prensky, M.: Digital Game-Based Learning. McGraw-Hill, New York (2001).

45. Roos, J., Roos, M.: Play is the Key. In: Thinking from Within. pp. 25-40. Springer (2006).

46. Rogers, C.R., Dorfman, E.: Client-centered: Its Current Practice, Implications, and Theory. ICON Group International (1951).

47. Axline, V.M.: Play therapy experiences as described by child participants. Journal of Consultation. Psychology. 14, 53 (1950).

48. Crenshaw, D.A., Kenney-Noziska, S.: Therapeutic presence in play therapy. Int. J. Play Ther. 23, 31 (2014).

49. Horne-Moyer, H.L., Moyer, B.H., Messer, D.C., Messer, E.S.: The use of electronic games in therapy: a review with clinical implications. Curr. Psychiatry Rep. 16, 1-9 (2014).

50. Sherlock, L.: Toward a rhetoric of serious game genres. Interdiscip. Model. Tools Serious Games Emerg. Concepts Futur. Dir. Emerg. Concepts Futur. Dir. 50 (2010).

51. Brahnam, S., Brooks, A.L.: Two innovative healthcare technologies at the intersection of serious games, alternative realities, and play therapy. Stud. Health Technol. Inform. 207, 153-162 (2014).

52. Wilkinson, N., Ang, R.P., Goh, D.H.: Online Video Game Therapy for Mental Health Concerns: A Review. Int. J. Soc. Psychiatry. 54, 370-382 (2008).

53. Gardner, J.E.: Can the Mario Bros. help? Nintendo games as an adjunct in psychotherapy with children. Psychother. Theory, Res. Pract. Train. 28, 667 (1991).

54. Barrett, M.S., Gershkovich, M.: Computers and psychotherapy: are we out of a job? (2014).

55. Sutton-Smith, B.: The Ambiguity of Play. Cambridge, Massachusetts, London, Harvard Univ. (1997).

56. Misuraca, G.: Digital Games for Empowerment and Inclusion ( DGEI ) D3 Final Vision and Roadmap A Roadmap for Action on Digital Games for Empowerment and Inclusion in Europe A Report of the Study : 1-20 (2012). 
57. Klimmt, C.: Serious Games and Social Change Why They (Should) Work. In: Ritterford, M. (ed.) Serious Games: Mechanisms and Effects. pp. 249-270. Routledge, New York (2009).

58. Martin, G., Steuter, E.: Pop Culture Goes to War: Enlisting and Resisting Militarism in the War on Terror. Lexington Books (2010).

59. Turkle, S.: The Second Self. MIT Press (2005).

60. Connolly, T.M., Boyle, E.A., Macarthur, E., Hainey, T., Boyle, J.M.: Computers \& Education A systematic literature review of empirical evidence on computer games and serious games. Computer Education 59, 661-686 (2012).

61. Katie Larsen McGlarty, A.O.P.M.F.R.P.D.V.V.A.M.: A Literature Review of Gaming. Gaming Education. 1-36 (2012).

62. Culin, S.: Retrospect of the Folk-lore of the Columbian Exposition. J. Am. Folk. 7, 51-59 (1894).

63. Holmes, W.H.: Twentieth Annual Report of the Bureau of American Ethnology, 1898-1899, (1903).

64. Sutton-Smith, B.: The kissing games of adolescents in Ohio. Midwest Folklore. 9, 189-211 (1959).

65. Opie, I.A., Opie, P.: Children's games in street and playground: chasing, catching, seeking, hunting, racing, duelling, exerting, daring, guessing, acting, pretending. Clarendon $\mathrm{P}$. (1969).

66. Sinclair, B.: Serious games stigmatized in and out of the industry, says Schell.

67. DiCebro, K.: Taking Serious Games Seriously in Education.

68. Juul, J.: Games telling stories. Game Stud. 1, 45 (2001).

69. Susi, T., Johannesson, M., Backlund, P.: Serious games: An overview. (2007).

70. Wolfe, J., Crookall, D.: Developing a scientific knowledge of simulation/gaming. Simulation Gaming. 29, 7-19 (1998).

71. Kolb, D.A.: Experiential learning: Experience as the source of learning and development. FT press (2014).

72. Crookall, D.: Serious games, debriefing, and simulation/gaming as a discipline. Simul. Gaming. 41, 898-920 (2010).

73. Bogost, I.: How to do things with videogames. Univertiy of Minnesota Press (2011).

74. Squire, K., Jenkins, H.: Harnessing the power of games in education. Insight. 3, 5-33 (2003).

75. Van Eck, R.: Digital Game-Based Learning: It's Not Just the Digital Natives Who Are Restless. Educ. Rev. 41, 16-30 (2006).

76. Kahne, J., Middaugh, E., Evans, C.: The Civic Potential of Video Games. MIT Press, Cambridge, Massachusetts (2008).

77. Young, M.F., Slota, S., Cutter, B., R., Jalette, G., Mullin, G., Lai, B., Simeoni, Z., Tran, M., Yukhymenko, M.: Our Princess Is in Another Castle: A Review of Trends in Serious Gaming for Education. Rev. Educ. Res. 82, 61-89 (2012).

78. Boocock, S.S., Schild, E.: Simulation games in learning. Sage Publications, California (1968).

79. Smith, R.: The Long History of Gaming in Military Training. Simul. Gaming . (2009).

80. Groff, J., Howells, C., Cranmer, S.: The impact of console games in the classroom : Evidence from schools in Scotland. Learning. 98 (2010).

81. Kent, S.: The Ultimate History of Video Games: from Pong to Pokemon and beyond... the story behind the craze that touched our li ves and changed the world. Three Rivers Press (2010).

82. Stone, R.J.: Serious gaming - virtual reality's saviour. In: Proceedings of Virtual Systems and MultiMedia annual conference, VSMM. pp. 773-786 (2005). 
83. Harris, J.L., Speers, S.E., Schwartz, M.B., Brownell, K.D.: US food company branded advergames on the internet: children's exposure and effects on snack consumption. J. Child. Media. 6, 51-68 (2012).

84. Griffiths, M.: The therapeutic use of videogames in childhood and adolescence. Clin. Child Psychol. Psychiatry. 8, 547-554 (2003).

85. Griffiths, M.: Video games and clinical practice: issues, uses and treatments. Br. J. Clin. Psychol. 36, 639-642 (1997).

86. Spence, J.: The use of computer arcade games in behaviour management. Mal. Ther. Educ. 6, 64-68 (1988).

87. Loftus, G.R., Loftus, E.F.: Mind at play; The psychology of video games. Basic Books, Inc. (1983).

88. Turkle, S.: Video games and computer holding power. Second self Comput. Hum. spirit. 64-92 (1984).

89. Chen, J.: Flow in Games and everything else. Commun. ACM. 50, 31-34 (2007).

90. Bowman, N.D., Weber, R., Tamborini, R., Sherry, J.: Facilitating game play: How others affect performance at and enjoyment of video games. Media Psychol. 16, 39-64 (2013).

91. Malone, T.: What Makes Things Fun to Learn? A Study of Intrinsically Motivating Video Games. , Palo Alto (1980).

92. Howard-Jones, P.: Neuroscience and Education: Issues and Opportunities. Semin. Ser. 28 (2007).

93. Richter, G., Raban, D.R., Rafaeli, S.: Studying gamification: the effect of rewards and incentives on motivation. In: Gamification in education and business. pp. 21-46. Springer (2015).

94. Nagle, A., Wolf, P., Riener, R., Novak, D.: The use of player-centered positive reinforcement to schedule in-game rewards increases enjoyment and performance in a serious game. Int. J. Seri. Games. 1, 35-47 (2014).

95. Papert, S.: Does easy do it? Children, games, and learning. Game Dev. Mag. (1988).

96. Egenfeldt-Nielsen, S.: Third generation educational use of computer games. J. Educ. Multimed. Hypermedia. 16, 263 (2007).

97. Bruckman, A.: Can Educational Be Fun?, (1999).

98. Chen, S.: Facing Edutainment's Dark Legacy, http://www.gamesandlearning.org/2016/01/25/facing-edutainments-dark-legacy/.

99. Reiber, L.: Seriously Considering Play. Educ. Technol. Res. Dev. 44, 43-58 (1996).

100. Cordova, D.I., Lepper, M.R.: Intrinsic motivation and the process of learning: Beneficial effects of contextualization, personalization, and choice. J. Educ. Psychol. 88, 715 (1996).

101. Garris, R., Ahlers, R., Driskell, J.E.: Games, motivation, and learning: A research and practice model. Simul. Gaming. 33, 441-467 (2002).

102. Arnab, S., Lim, T., Carvalho, M.B., Bellotti, F., De Freitas, S., Louchart, S., Suttie, N., Berta, R., De Gloria, A.: Mapping learning and game mechanics for serious games analysis. Br. J. Educ. Technol. 46, 391-411 (2015).

103. Gunter, G.A., Kenny, R.F., Vick, E.H.: Taking educational games seriously: Using the RETAIN model to design endogenous fantasy into standalone educational games. Educ. Technol. Res. Dev. 56, 511-537 (2008).

104. Bedwell, W.L., Pavlas, D., Heyne, K., Lazzara, E.H., Salas, E.: Toward a Taxonomy Linking Game Attributes to Learning: An Empirical Study. Simul. Gaming. 43, 729-760 (2012).

105. Aarseth, E.: Computer game studies, year one. Game Stud. 1, 1-15 (2001).

106. Clements, M.T., Ohashi, H.: Indirect network effects and the product cycle: video games in the US, 1994-2002. J. Ind. Econ. 53, 515-542 (2005). 
107. Howell, K.: Games for health conference 2004: issues, trends, and needs unique to games for health. CyberPsychology Behav. 8, 103-109 (2005).

108. Michael, D.R., Chen, S.L.: Serious games: Games that educate, train, and inform. Muska \& Lipman/Premier-Trade (2005).

109. Zyda, M.: From visual simulation to virtual reality to games. Computer (Long. Beach. Calif). 38, 25-32 (2005).

110. Wittgenstein, L., Anscombe, G.E.M., Hacker, P.M.S., Schulte, J.: Philosophische Untersuchungen: Philosophical Investigations. Wiley-Blackwell (2009). 